Original Research Paper

\title{
Motor Oil Viscosity Stratification in Friction Units of Marine Diesel Motors
}

\author{
Sergey Viktorovich Sagin and Oleksandr Vladymyrovich Semenov \\ Department of Marine Power Plants, Odessa National Maritime Academy, Odessa, Ukraine
}

\author{
Article history \\ Received: 21-01-2016 \\ Revised: $10-02-2016$ \\ Accepted: 15-02-2016 \\ Corresponding Author: \\ Sergey Viktorovich Sagin, \\ Department of Marine Power \\ Plants, Odessa National \\ Maritime Academy, Odessa, \\ Ukraine \\ Email: saginsergey@mail.ru
}

\begin{abstract}
The phenomenon of the motor oil viscosity stratification in lubricating the cylinder-piston units of marine diesel engines has been investigated. The correlations for determining the shear stress and the velocity, occurring in the liquid flow between the parallel planes, have been given. The modes of the hydrodynamic and the boundary lubrication, taking place in the cylinder assembly of the marine diesel engine operation, have been considered. The methodology has been introduced for determining the viscosity of the boundary layer, which separates the surfaces of the piston ring and that of the cylinder bushing in the marine diesel motor operation. The results of the experiments, confirming the presence of the viscosity stratification in the boundary lubrication layer of the marine motor oil, have been submitted.
\end{abstract}

Keywords: Marine Diesel Motor Oil, Marine Diesel Engine CylinderPiston Assembly, Hydrodynamic Lubrication, Boundary Lubrication, Liquid Flow, Shear Velocity, Viscosity Curve, Volumetric Viscosity, Boundary Layer Viscosity, Viscosity Stratification

\section{Introduction}

Black oil and its derivative oil systems (petroleum fuels and petroleum oils) are the subjects of study in many natural sciences, each of which makes definite contribution to developing the ideas of the composition and the structure of those systems (Gureyev et al., 1986). From the viewpoint of organic chemistry, petroleum oils represent a mixture of low- and high-molecular compounds, related to different homologous series. From the perspective of analytical chemistry, petroleum oil, as an element of oil structure, represents mixtures of organic compounds with complex composition. Considered in terms of colloidal chemistry, petroleum oil, obtained from black oil, is a complex multicomponent mixture, which, depending on the external environment, reveals the properties either of a molecular mixture or of a disperse system (Lashkhi, 1996). At the same time the system acquires the following features:

- $\quad$ Structural and mechanical strength

- Instability; capacity for phase stratification

The structural and mechanical strength of the system improve the lubricating capacity of motor oil. This property acquires special practical importance for the modes of boundary lubrication, when the additional disjunctive (wedge) pressure occurs within the lubrication layer, increasing the carrying capacity of the oil wedge.

The oil performance in marine diesel engines is associated with change of its physical and chemical state, including deformation. For the lubricating material, placed in the contact area, the major attributes of deformation are as follows: The presence of the externally applied mechanical force and shape change, represented by displacement of particles of the matter (the molecules in this case) in relation to each other. Considering the friction unit, the piston ring-the cylinder bushing, the oil molecules are affected by the mechanical force, in this case, by the normal force, pressing the piston to the cylinder wall. The applied load generates the internal forces, counteracting the external ones, which are equal, but directionally opposite to them. Pressure $P$ occurs in the lubrication layer, equal to the force per unit area ratio:

$$
P=\frac{F}{S}
$$

Force and stress can be distinguished as normal (pressure) and tangential ones (shear strength). For the piston ring-cylinder bushing friction pair the destructive 
impact on the oil layer is affected by the shear stress, tearing oil molecules from the contacting surfaces.

Thus, the rheological properties of oil material, placed in the piston ring-cylinder bushing tribological assembly, are properly characterized by the shear stress, which may be defined as:

$\tau=\frac{F}{S}$

Newton law for so-called true-viscose (Newtonian) liquids determines the relations between the external stress and the velocity of the particular layers movement:

$P=\frac{F}{S}=\eta \frac{d u}{d x}$

Where

$\eta \quad=$ The dynamic viscosity, $\mathrm{Pa} \cdot \mathrm{s}$

$\frac{d u}{d x}=$ The velocity gradient (Shramm, 2003)

In this formula the proportionality factor $\eta$ is the dynamic viscosity of the system, being the material constant of the liquid at a given temperature. Given (1), Equation 2 can be written as follows:

$$
\tau=\eta \cdot \gamma^{\prime}
$$

where, $\gamma^{\prime}$ is shear velocity.

The shear stress and shear velocity can be illustrated by the parallel planes model (Fig. 1), which is representative of friction processes in the piston ringcylinder bushing assembly.

The shear stress $\tau$ stipulates the characteristic pattern of velocity distribution in the liquid layers. The maximum flow velocity $v_{\max }$ is observed at the boundary between the liquid and the movable plane. As the distance from the movable plane increases, the flow velocity becomes lower and at the distance $y, v_{\min }=0$ at the boundary with the stationary plane, the shear velocity $\gamma^{\prime}$ is a velocity gradient across the gap and it is mathematically expressed as a differential:

$\gamma^{\prime}=\frac{d v}{d y}, \frac{\mathrm{m} / \mathrm{s}}{\mathrm{m}}=\mathrm{s}^{-1}$

The correlation between the shear stress and the shear velocity, characterizing the behavior of liquid while flowing, is graphically represented as a curve, where the values of the shear stress $\tau$ are located on axis of ordinates and the values of the shear velocity $\gamma^{\prime}$ are located on axis of abscissas. This graph is called a "flow curve".

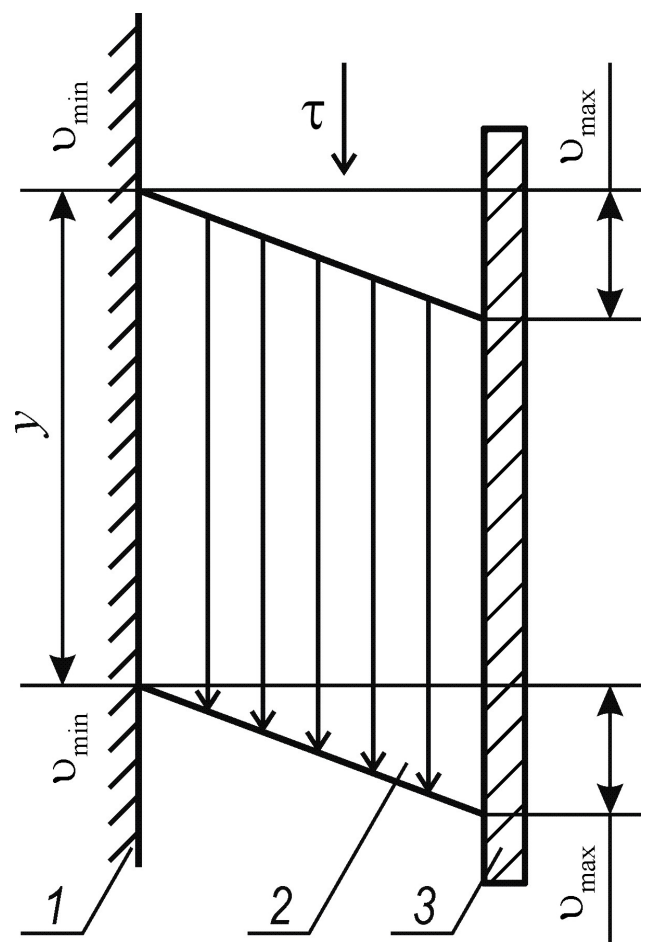

Fig. 1. Model of the liquid flow between the parallel planes: 1stationary plane; 2-liquid; 3-movable plane

The simplest type of the flow curve is shown in Fig. 2a. In this case the viscosity in Equation 3 is assumed to be constant, independent of shear velocity. The graphic equivalent of Newton Equation 3 will be presented by a direct line with inclination $\alpha$, starting at the origin of coordinates (Fig. 2a). Any point on this line will be identified by two values: $\tau$ and $\gamma^{\prime}$. The first value divided by the second value will give the magnitude of $\eta$. The magnitude $\eta$ can also be defined as a tangent of angle $\alpha$.

Another widely applied plot is the function $\eta=\mathrm{f}$ $(\gamma)$, called a "viscosity curve" (Fig. 2b). Since the flow curve of the Newtonian liquid is, in fact, a direct line, the $\tau$ to $\gamma^{\prime}$ ratio in all pairs of values, located on this line, is constant. This means that the shear velocity change does not affect $\eta$.

Along with the normal liquids there are also the abnormally viscose systems, revealing increased viscosity value at low pressure; this occurs due to the fact that the specific peculiar space structures are formed within them as a result of the disperse phase particles interaction.

The majority of disperse systems possess the abnormal character of viscosity, i.e., they do not conform to Newton law. Such systems (and, as a consequence, the liquids which form them) are called non-Newtonian. The viscosity of such liquids is a function of stress, of shear. Basic reason for abnormal 
viscosity could be explained by the space structure, appearing when the disperse phase particles interact with each other. As regards the rheological properties, the structured systems occupy intermediate position between the liquids and solids. The structured thin layers of the lubricating material, placed in the narrow gap in the metallic piston ring-cylinder bushing friction pair, could be associated with such systems. The presence of the space structure imparts to those systems the peculiar mechanical properties: Elasticity, strength, plastic viscosity (Kiriyan and Altois, 2008; Akhmatov, 1963).

The types of non-Newtonian liquids are much more numerable than those of the ideal liquids. They include the dilatant liquids and the pseudo-plastic liquids, in which the shear strength and viscosity depend on the shear velocity. The flow and the viscosity curves are shown in Fig. 3 (Shramm, 2003).

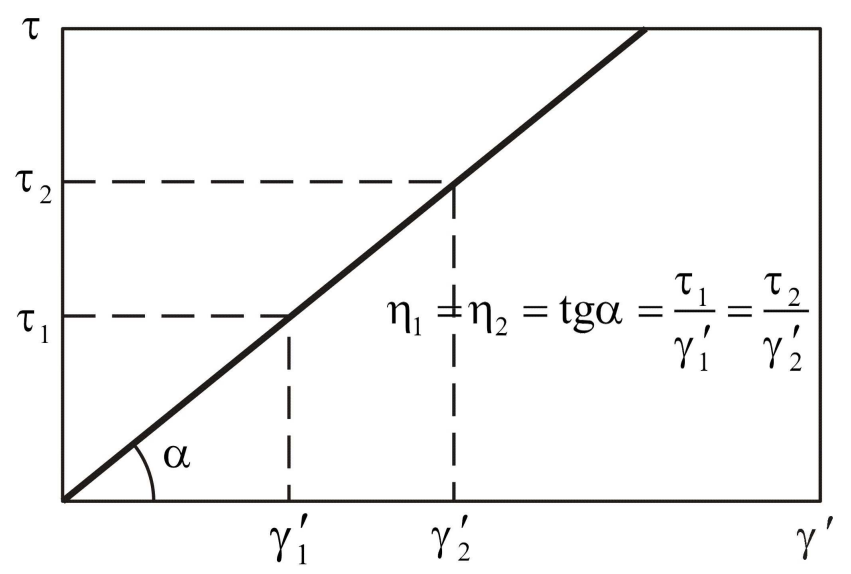

(a)
The plastic flows of the disperse systems are described by the Shvedov-Bingham equation:

$$
P-P_{\mathrm{d}}=\eta^{\prime} \frac{d u}{d x}
$$

Where:

$\eta^{\prime}=$ Viscosity, corresponding to the plastic flow of the system

$P_{d}=$ The yield point, i.e., the critical shearing strength that is required for breaking the structure and for starting the flow

In the range of stresses lower than $P_{\mathrm{d}}$ the system reveals elastic properties; at $P>P_{\mathrm{d}}$ the plastic deformation is observed. When $P_{\mathrm{d}}=0$, the ShvedovBingham equation transforms into the Newton equation (Kozitskiy and Polischuk, 2011).

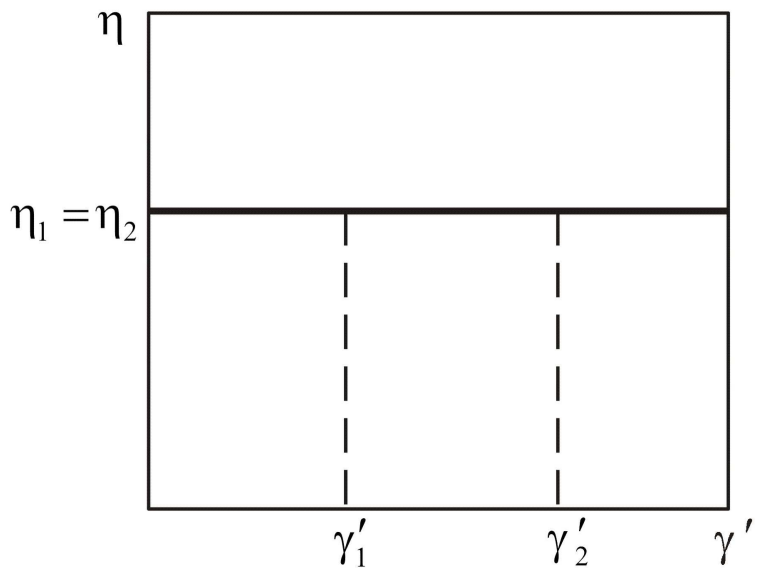

(b)

Fig. 2. Flow curve (a) and viscosity curve (b) for Newtonian liquid

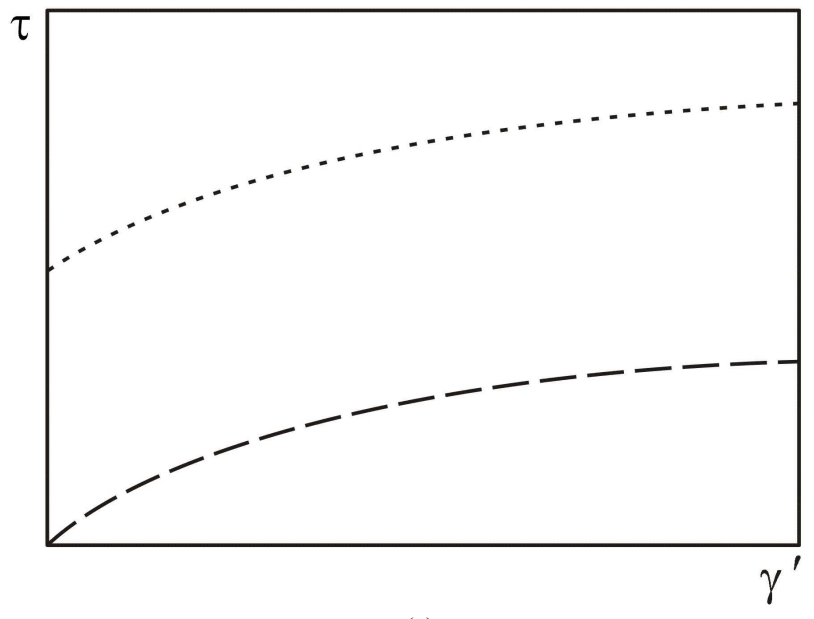

(a)

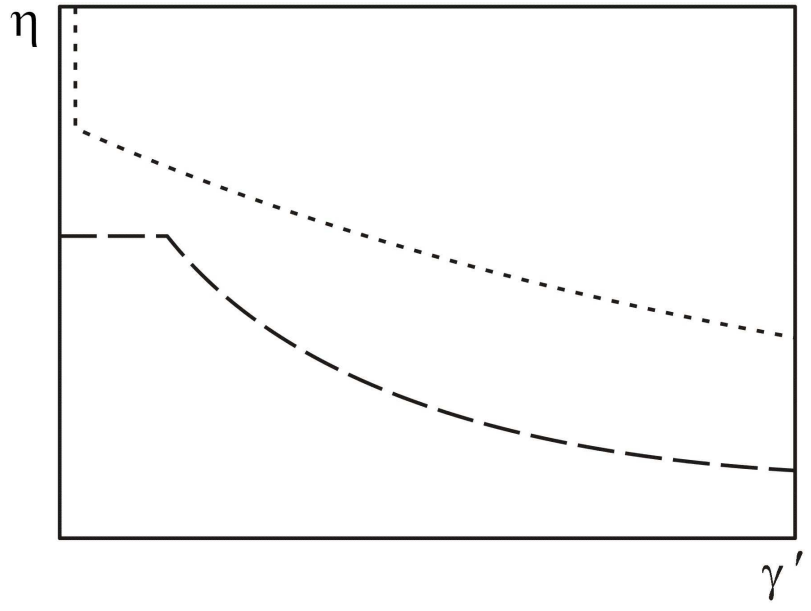

(b)

Fig. 3. Flow curve (a) and viscosity curve (b) for non-Newtonian liquids 


\section{Materials and Methods}

The piston ring-cylinder bushing system of the marine internal combustion engine is a standard tribological system consisting of two metallic parts, separated by a layer of the lubricating material. Such system is characterized by the following features: Composition (the parts and the properties of the parts of the system); internal connections (connections between the parts of the system); external connections (input, output); functional systems (input-output correlation).

Lubricating material is a basic component in the piston ring-cylinder bushing system, at which a control action can be focused. Its properties are not only determined by its intrinsic structure, but they are also affected by the metallic surfaces which are separated by this material (Garkunov, 1989). The lubricating material, placed in the piston ring-cylinder bushing tribological assembly, possesses some individual features, which do not change in the "basic" option independently of the system in which it is placed, as well as some aggregate features.

The characteristics of the lubrication material, included in the piston ring-lubricating layer-cylinder bushing system, are, as a rule, described in terms of the hydrodynamic theory of lubrication (Kostetskiy, 1970; Gots et al., 1999). Moreover, only "volumetric" properties of the lubrication material are taken into account and no abnormality of those properties, occurring in the thin boundary layers and caused by their liquid-crystalline structures, is ever considered. A distinguishing feature of the lubricating material, included in the tribological system under consideration, is its capacity to form the structured boundary layers, possessing the properties of the liquid crystals. In this case some individual properties of the thin layers of liquid differ from the similar properties observed in large volumes of liquid (Altois and Popovskiy, 1996). The liquid-crystalline state of the lubricating material boundary layer results in anisotropy of some of its properties, such as viscosity and strength in particular (Sagin and Matskevich, 2010).

One of the founders of the studies on abnormal boundary-layer properties of liquids close to hard surfaces was Deryagin and Churayev $(1983 ; 1984)$. He put forward a hypothesis that there was a certain class of liquids, which, affected by van der Waals force field, generated by the hard substrate, could create thin layers directionally arranged. As a result of his experiments, it was established that the layers adjoining the hard substrate are the ones that are most affected by the surface forces; the effect of the surface force is not, however, limited by the monomolecular layer, but is propagated throughout the depth of the entire layer.

Multi-molecular theory of boundary friction has been confirmed by the studies of Akhmatov (1963), where the effect of the hard metallic substrate surface forces used to be estimated as propagating to the tenths of a micron. The abovementioned investigations were undertaken for aromatic hydrocarbons and could not properly characterize the phenomena of the boundary friction and the boundary lubrication with the components of the marine machinery.

In terms of the lubrication materials applied for lubricating marine machines and mechanisms the boundary friction phenomenon was studied in the papers dedicated to operating oil circulation systems of the marine diesel engine (Popovskiy et al., 1996; Sagin et al., 1998), which, in contrast to the previous studies, considered the three-phase metal-lubricant-metal tribological system and proved the possibility of using the disjoining (wedge) pressure effect discovered earlier by (Slobodyanyuk et al., 2013).

Investigating the boundary layer structures facilitates determining the type of their orientation relative to the metal surface. Molecules can be located in the oil boundary layer both perpendicularly (homeotropically) and in parallel (planar-directed) to the hard surface.

The basic modes of friction and of the associated lubrication in the marine diesel engines are the hydrodynamic and the boundary ones. Notwithstanding the purpose of the hydrodynamic lubrication mode in the piston ring-cylinder bushing tribological assembly of the marine diesel engine, the lubrication process of this unit occurs in the boundary friction mode. This is stipulated by several factors, the most important of which being the minimum gap within the piston ring-cylinder bushing friction pair, intended to secure the tightness of the combustion chamber and to maximize the conversion of the expanding cylinder gases into the efficient operation. Besides, in the course of operation, at the surfaces of this pair, the oxides are formed and the carbon deposits are generated, which makes the gap even narrower and causes the hydrodynamic mode transition into the mixed or boundary friction mode.

The principle of the cylinder assembly lubrication mode can be illustrated by the model shown in Fig. 4 .

The hydrodynamic lubrication mode occurs in the places, where the lubrication material separates the surfaces of the piston and of the bushing. In the piston ring-cylinder bushing friction pair the mode of friction and lubrication becomes the boundary one. This occurs because of the thermal expansion of the ring (due to the presence of the "ring" lock) and also because of the fact that the ring performs a compression action, when both the external and the internal parts of the ring are affected by gases and the outer surface of the ring is pressed against the surface of the cylinder bushing. In this case, the gaps in the friction pairs of pistonbushing $\Delta_{p}$ and of ring-bushing $\Delta_{r}$ have different values and correspond to different friction modes. 


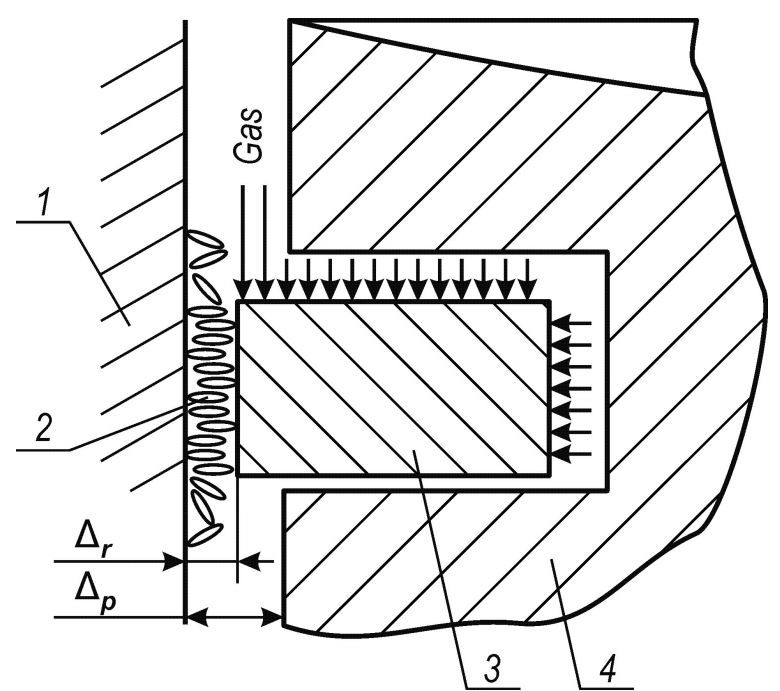

Fig. 4. Cylinder bushing-lubrication material-piston ring tribological system model: 1-cylinder bushing; 2lubrication material; 3-ring; 4-piston

The characteristics of the lubrication material, included in the piston ring-lubricating layer-cylinder bushing tribological system, are, as a rule, described in terms of the hydrodynamic lubrication theory. In this regard, only the "volumetric" properties of the lubrication material are taken into account and the abnormality of those properties, occurring in the thin boundary layers, caused by their liquid crystalline structure, is not considered.

It was noted for several times that the characteristics of the thin lubrication layers, generated under boundary friction conditions, depend not only on the state of the oil structure, but also on the effect produced by the adjacent hard substrate (Kiriyan and Altois, 2008; Sagin and Zabolotskiy, 2011). Generation of the structured liquid-crystalline layers with anisometric molecule shapes near the hard surface (especially, near the metallic surface) results in considerable difference between the physical properties of the thin layers of liquid and the properties of this liquid in the "volumetric" phase. The clearly observed structural heterogeneity of the boundary lubricating layers, predetermining the non-Newtonian character of viscose flow, affects considerably the dissipative properties of the lubricating material, especially of that in the tribological units, operating in the mode of boundary and mixed friction. Viscosity is one of the parameters, having different values in case of volumetric liquid and boundary layer (Matskevich, 2013).

To confirm this statement, the friction processes were modeled for lubricating the cylinder-piston assembly of 12K98ME-C7 marine diesel engine, manufactured by DOOSAN-MAN-B\&W, installed as a main motor at the vessel APL Southampton, deadweight of 131,360 tones. Basic features of the diesel engine are as follows:

- Diesel type-two-stroke, crosshead engine

- $\quad$ Rated power- $N_{\text {nom }}=54120 \mathrm{kWt}$

- Rated rotation frequency- $n_{\mathrm{nom}}=97 \mathrm{rev}^{-1}$

- Number of cylinders-12

- Cylinder diameter- $D=0,98 \mathrm{~m}$

- Piston stroke- $S=2,66 \mathrm{~m}$

- Lubrication system of the cylinder-piston unitlubrication (cylinder)

The cylinder-piston unit of the diesel engine was lubricated with Mobilgard 570 oil supplied by Mobil, the basic characteristics of which are shown in Table 1.

The purpose of the investigation was to determine the oil viscosity stratification, occurring in the boundary lubrication layer under changing shear loads, which (in turn) depend on the piston movement velocity and can be predetermined by the crankshaft rotation frequency and by the diesel engine power.

\section{Results}

Oil located in the gap of the piston ring-cylinder bushing friction pair is affected by shear stress. In this case the shear velocity $\gamma^{\prime}$ can be calculated according to (4), knowing the linear velocity of the piston movement and the geometric dimensions of the piston ring:

$\gamma^{\prime}=\frac{v_{m}}{h_{r}}$

where, $\mathrm{v}_{m}$ is the average velocity of the piston, $\mathrm{m} / \mathrm{s}$, which is, in turn, determined as follows:

$v_{m}=\frac{S n}{30}$

Where:

$S=$ The piston stroke, $\mathrm{m}$

$n=$ The frequency of the crankshaft rotation, $\mathrm{rev}^{-1}$

$h_{\mathrm{K}}=$ The height of the piston ring, $\mathrm{m}$

The range of the operational modes of the considered diesel engine is determined by the rotation frequency from the minimum stable one $n_{\min }$ up to the maximum rated $n_{\max }=1.03 n_{\mathrm{e}}$ and is set within the interval of $53 \ldots 100 \mathrm{rev}^{-1}$. Then, taking into account the geometric dimensions of the diesel engine piston ring $h_{r}=0.025 \mathrm{~m}$ and also according to (5) and (6), the shear velocity in the piston ring-cylinder bushing friction pair amounts to $\gamma^{\prime}=188 \ldots 355 \mathrm{~s}^{-1}$. 


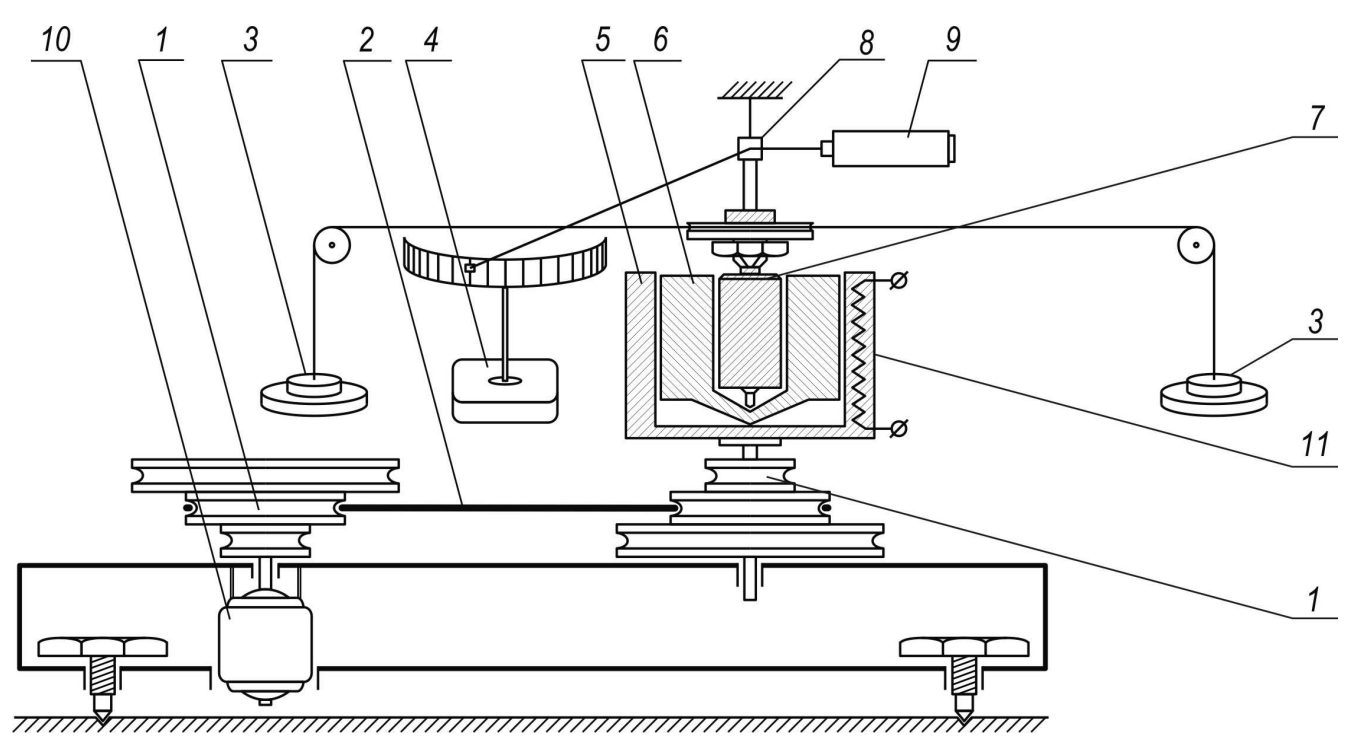

Fig. 5. Schematics of rotation viscometer: 1-pulleys; 2-belt; 3-weights (counterbalance); 4-dial scale; 5-cup (the place where the external cylinder is set); 6 -external cylinder or the rotation pair; 7-internal cylinder of the rotation pair; 8-mirror; 9-laser; 10electric motor; 11 -electric resistance thermometer

Table 1. Basic characteristics of the motor oils used for the experiment

\begin{tabular}{lcccc}
\hline Typical characteristics & Mobilgard 570 & Energol CLO50M & Cyltech70 & Texaco Special HT70 \\
\hline SAE number & 50 & 50.0 & 50.0 & 50 \\
Kinematic Viscosity: & & & & 218.0 \\
at $40^{\circ} \mathrm{C}, \mathrm{sSt}$ & 229 & 217.0 & 19.5 & 20 \\
at $100^{\circ} \mathrm{C}, \mathrm{sSt}$ & 21 & 70.5 & 70.0 & 70 \\
Total Base Number (TBN), $\mathrm{mgKOH} / \mathrm{g}$ & 70 & 940.0 & 938.0 & 940 \\
Density at $15^{\circ} \mathrm{C}$, & 942 & 215.0 & 223.0 & 207 \\
Flash point, ${ }^{\circ} \mathrm{C}$, & 241 & &
\end{tabular}

The oil viscosity in the boundary lubrication layer at different shear velocities was measured with the help of the rotary viscometer developed by (Altois et al., 2005; Kiriyan and Altois, 2010). The viscometer operation principle (Fig. 5) is based on determining the viscose friction torque, which occurs in the liquid layer between the coaxial cylinders 6,7 when the external cylinder is rotated in the cup 5. It is driven by the electric motor 10 through the belt gear 2 of the pulley system 1. The system of counterbalances 3 is used as the viscose friction torque meter. The possibility of varying the weights of these counterbalances ensures the considerable range of the measured viscosity values in the oils under investigation $(10 \ldots 200 \mathrm{sSt})$, as well as the velocity values of their shear deformations $\left(\gamma^{\prime}=10^{2} \ldots 10^{4} \mathrm{~s}^{-1}\right)$.

The restoring torque, compensating the viscose friction torque, was calculated using beam deflection angle $\varphi$, identified by the dial scale 4 , reflected from the mirror 8 when it is spotted by laser 9 . The gap width between the cylinders 6 and 7 (the liquid layer thickness) is set by varying the diameters of the available internal replaceable cylinders. The temperature mode in the contact area can be altered and controlled with the help of the electrical resistance thermometer 11 .

In this case, it was possible to determine the lubricating material viscosity in the boundary lubricating layer $v_{b l}$ for different shear velocities. Its value was determined at the lubricating layer thickness of 15 micrometers, which corresponded to the operational gap in the piston ring-cylinder bushing friction pair. The value of the volumetric viscosity $v_{v o l}$ was found with the help of capillary viscometer supplied by Unitor. The experiments, both for determining the volumetric viscosity for $v_{v o l}$ and for determining the viscosity in the boundary lubricating layer $v_{b l}$, were implemented at a temperature of the lubricating material of $40^{\circ} \mathrm{C}$.

Laboratory investigations were undertaken with Mobilgard 570 motor oils (supplied by Mobil) which were used for marine diesel engine operation, as well as with the motor oils of several leading companies: Energol CLO50M (BP), Cyltech70 (Castrol), Texaco Special HT70 (Chevron). Those motor oils had similar values of the basic characteristics (Table 1) and, therefore, they could be compared in the experiment. 


\section{Discussion}

The results of measuring the volumetric viscosity, as well as of measuring the viscosity of the boundary lubricating layer at different shear velocities are given in Table 2 and illustrated in Fig. 6.

As a result of the investigations, viscosity-shear velocity ratio (Fig. 6) confirmed the "non-Newtonian" character of the lubricating material in the narrow gap of the piston ring-cylinder bushing friction pair. The empirical relations, discovered for the motor oils of the principal manufacturers, shown in Fig. 6, match well with the relationships, illustrating the plastic flow theory, shown in Fig. 3. Besides, the obtained results confirmed the earlier statement, that, in the friction trios, the boundary lubricating layers adjoining the metal surface are more viscose due to the presence of the directionally arranged molecules within them (Kiriyan and Altois, 2008; Popovskiy et al., 1996; Sagin, 2014).

Table 2. The results of the marine motor oil rheological tests

\begin{tabular}{|c|c|c|c|c|c|c|c|c|c|c|}
\hline \multirow{3}{*}{$\begin{array}{l}\text { Type of the lubrication material } \\
\text { and its characteristics }\end{array}$} & \multicolumn{10}{|c|}{ Rotation frequency of the shaft of the diesel engine, $n, r p m$} \\
\hline & \multicolumn{10}{|c|}{ 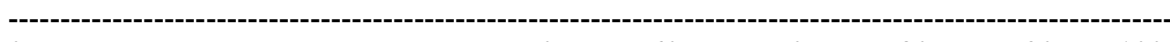 } \\
\hline & 0 & - & - & - & 50 & 60 & 70 & 80 & 90 & 100 \\
\hline & \multicolumn{10}{|c|}{ Shear velocity, $\mathrm{g}^{\prime}, \mathrm{c}^{-1}$} \\
\hline & 0 & 50 & 100 & 150 & 177 & 213 & 248 & 284 & 319 & 355 \\
\hline \multicolumn{11}{|l|}{ Mobilgard570 } \\
\hline Volumetric viscosity, $v_{v o l}, \mathrm{sSt}$ & 228 & & & & & & & & & \\
\hline Boundary layer viscosity, $v_{\mathrm{bl}}, \mathrm{sSt}$ & 256 & 239 & 233 & 223 & 221 & 219 & 218 & 216 & 215 & 214 \\
\hline \multicolumn{11}{|l|}{ Energol CLO50M } \\
\hline Volumetric viscosity, $v_{v o l}, \mathrm{sSt}$ & 217 & & & & & & & & & \\
\hline Boundary layer viscosity, $v_{\mathrm{bl}}, \mathrm{sSt}$ & 228 & 218 & 213 & 206 & 203 & 201 & 198 & 197 & 195 & 194 \\
\hline \multicolumn{11}{|l|}{ Cyltech70 } \\
\hline Volumetric viscosity, $v_{v o l}, \mathrm{sSt}$ & 218 & & & & & & & & & \\
\hline Boundary layer viscosity, $v_{\mathrm{bl}}, \mathrm{sSt}$ & 239 & 223 & 216 & 209 & 207 & 206 & 204 & 203 & 202 & 201 \\
\hline \multicolumn{11}{|l|}{ Texaco Special HT70 } \\
\hline Volumetric viscosity, & 222 & & & & & & & & & \\
\hline
\end{tabular}

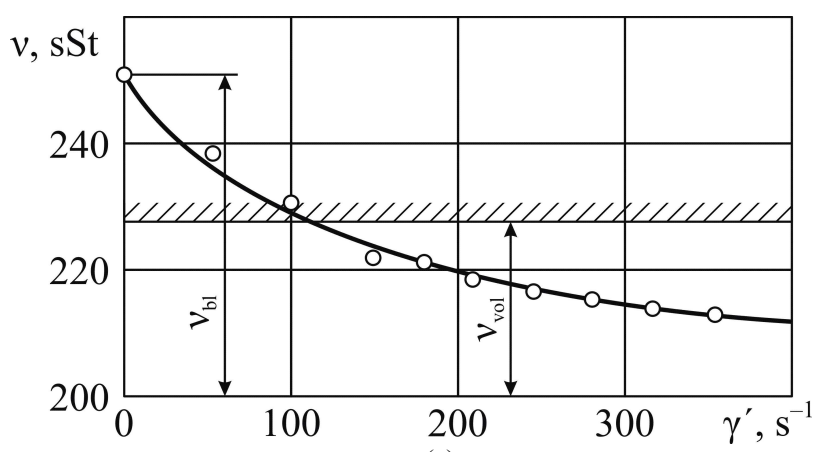

(a)

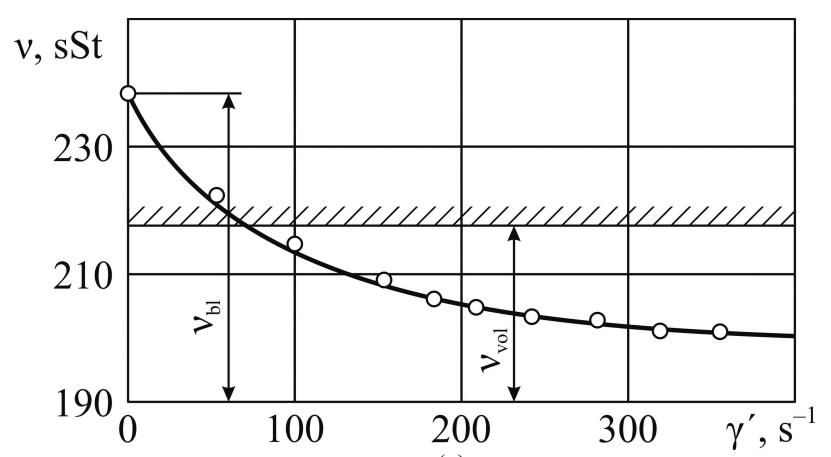

(c)

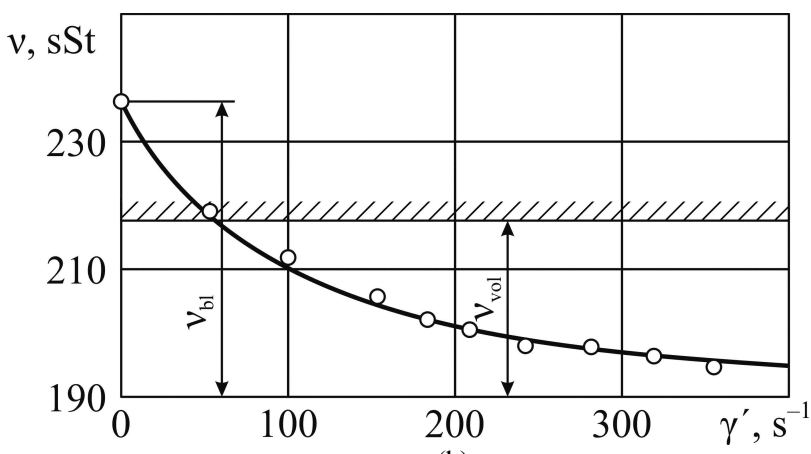

(b)

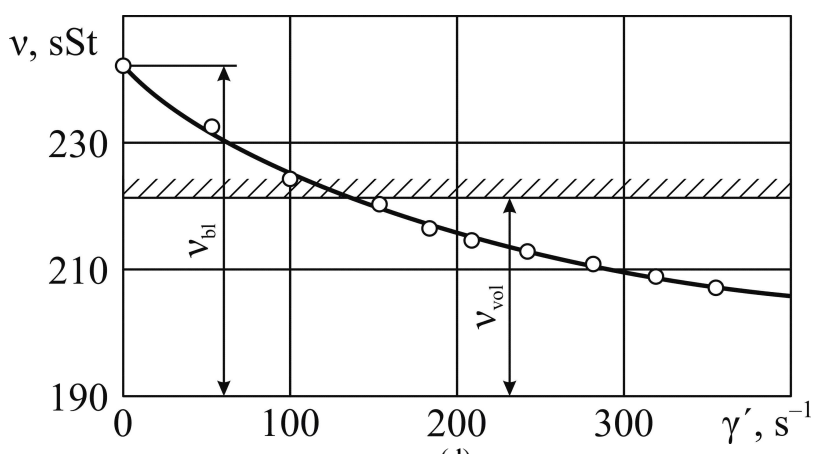

(d)

Fig. 6. The motor oil viscosity curves (in the boundary layer, $v_{b l}$ and in the large volume $v_{v o l}$ ) depending on the shear velocity $\gamma^{\prime}$ at the oil layer thickness of 15 micrometers: (a) Mobilgard570 lubrication oil; (b) Energol CLO50M lubrication oil; (c) Cyltech70 lubrication oil; (d) Texaco Special HT70 lubrication oil 


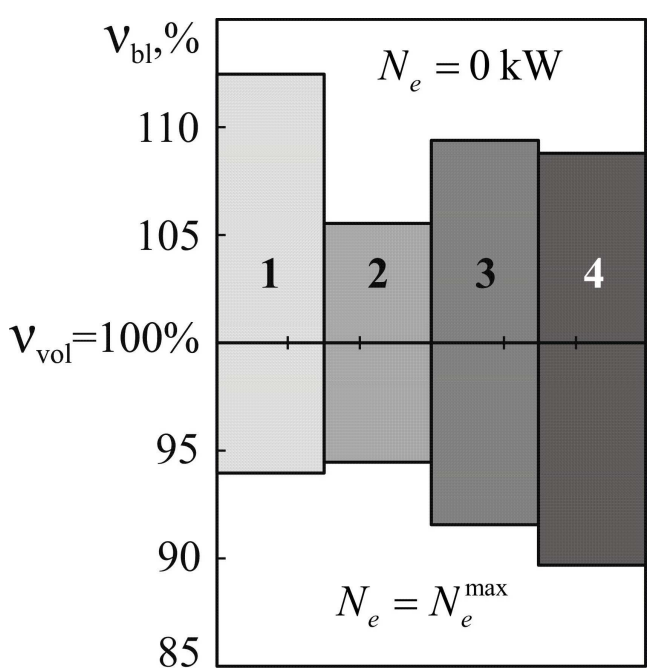

Fig. 7. The diagram of the marine motor oil viscosity stratification depending on the diesel engine load: 1lubrication oil Mobilgard570; 2-Energol CLO50M lubrication oil; 3-Cyltech70 lubrication oil; 4-Texaco Special HT70 lubrication oil

The viscosity stratification across the lubrication layer depth confirms the liquid-crystalline nature of the boundary layer structure in the narrow gap between the piston ring and the cylinder bushing. In the range of the shear velocities of $\gamma^{\prime}=0 \ldots 400 \mathrm{c}^{-1}$ (corresponding to the basic operation modes of the marine slow-running diesel engines), the viscosity stratification of different motor oils amounts to $(0.9 \ldots 1.12)$ of the volumetric viscosity value $v_{v o l}$. For the motor oils under investigation, the motor oil viscosity stratification is shown in Fig. 7, where the upper part of the diagram corresponds to the lack of shear stresses $\left(N_{e}=0 \mathrm{kWt}\right)$ and the lower part corresponds to shear stresses under maximum load $\left(N_{e}=N_{e}^{\max }\right)$.

\section{Conclusion}

As a result of the investigations, it was established that the lubricating material, located in the narrow gap in the cylinder bushing-lubricating material-piston ring tribological system of the marine slow-running diesel engines is a radial-anisotropic liquid, characterized by different values of viscosity across the oil layer depth.

The mechanical loads, affecting the arranged molecular layers of the boundary lubricating layer, result in their destruction, which decreases the viscosity value and deteriorates the dampening properties of the oil.

While increasing the diesel engine shaft rotation frequency (and, as a consequence, the piston velocity as well) the shear loads occur in the oil layer which decrease its viscosity. This fact should be taken into account when selecting the oil grade for lubricating the cylinder-piston unit and also when specifying the oil rejection criteria, so far as in both cases the value of viscosity is determined for a large volume of liquid, but the cylinder-piston unit operates with the viscosity value characteristic for the boundary layer.

It should be noted that when there are no shear loads and at the starting movements of the contact surfaces, the boundary lubricating layer viscosity exceeds the volumetric oil viscosity by $10 \ldots 12 \%$. This effect is especially important for the start-up operation mode of the marine diesel engines, when the velocity of the piston movement does not allow for a smooth distribution of the oil film across the surface of the cylinder bushing ensuring the required lubrication mode.

\section{Acknowledgement}

The authors are thankful to B.A. Altoise, Doctor of Physics and Mathematics, Professor and to S.V. Kiriyan, Candidate of Physics and Mathematics, for the support in performing the experimental investigations and also to Vladimir A. Golikov, Scientific Research Vice Rector of Odessa National Maritime Academy, Doctor of Technical Science, Professor for the support in developing the plan and the methodology for the scientific researches, as well as for the recommendations on organizing the process of the experiment and on finalizing the results of the study.

\section{Funding Information}

The investigations have been carried out according to the plan of performing the research and development studies at Odessa National Maritime Academy on the subject "Developing the systems and methods for improving the technical operation of the marine power plants based on modern information technologies".

\section{Author's Contributions}

Sergey Viktorovich Sagin: Organized theoretical description of lubrication processes, experimental researches in the scientific laboratory, results analysis and finalization.

Oleksandr Vladymyrovich Semenov: Contributed to the experimental research at the marine diesel engine in sea-craft conditions, results analysis and finalization.

\section{Ethics}

This article is original and contains unpublished material. The corresponding author confirms that all of the other authors have read and approved the manuscript and no ethical issues involved. 


\section{References}

Altois, B.A., S.K. Aslanov and A.F. Butenko, 2005. Rotational viscometer for micron layer study. Phys. Air-Disperse Syst., 42: 53-65.

Altois, B.A. and Y.M. Popovskiy, 1996. Physics of surface layers of liquids. Astroprint, Odessa.

Akhmatov, A.S., 1963. Molecular physics of boundary lubrication friction. Fizmatgiz, Moscow.

Garkunov, D.N., $1989 . \quad$ Triboengineering. Mashinostroyeniye, Moscow.

Gots, A.N., S.V. Putintsev and S.A. Anikin, 1999. Conditions for cylinder-piston unit parts lubrication and friction in the internal combustion engines. Proceedings of the Research and Practical Seminar "Improving the Power, Economic and Environmental Indicators of the Internal Combustion Engines, (ICE' 99), Vladimir, pp: 164-166.

Gureyev, A.A., I.G. Fuks and V.L. Lashkhi, 1986. Chemmotology. Khimiya, Moscow.

Deryagin, B.V. and Y.V. Churayev, 1983. Surface forces. Nauka, Moscow.

Deryagin, B.V. and Y.V. Churayev, 1984. Wetting films. Nauka, Moscow.

Kiriyan, S.V. and B.A. Altois, 2010. Rheology of motor oils with quasi liquid-crystalline layers in friction trio. Friction Wear, 31:312-318.

Kiriyan, S.V. and B.A. Altois, 2008. Epitropic liquidcrystalline layers in synthetic oils and their effect on shear flow. Phys. Air-Disperse Syst., 45: 72-77.

Kozitskiy, S.V. and D.D. Polischuk, 2011. Mechanics. Astroprint, Odessa.

Kostetskiy, V.I., 1970. Friction, lubrication and wear in machines. Tekhnika, Kiev.

Lashkhi, V.L., 1996. The idea of operational characteristics of fuels and lubricants as colloidal systems. Chem. Technol. Fuels Oils, 3: 32-33.
Matskevich, D.V., 2013. Controlling the rheological characteristics of motor oils in marine diesel engines. Problems Mechan., 2: 52-60.

Popovskiy, Y.M., S.V. Sagin, S.A. Khanmamedov and M.N. Grebenyuk, 1996. Effect of anisotropic liquids on friction units operation. Herald Mechanical Eng., 6: 7-11.

Sagin, S.V. and Y.V. Zabolotskiy, 2011. Determining the surface tribotechnical characteristics by the degree of wall layers arrangement in hydrocarbon liquids. Problems Mechan., 3: 78-88.

Sagin, S.V. and D.V. Matskevich, 2010. Optical characteristics of boundary layers of the oils applied in marine engine circulation systems. Marine Power Plants: Odessa, 26: 116-125.

Sagin, S.V., S.A. Frasinyuk and S.A. Khanmamedov, 1998. Improving the efficiency of marine diesel motor operation by controlling the structure of lubricating layer. Marine Power Plants: Odessa, 2: 89-94.

Sagin, S.V., 2014. Investigating the correlation between liquid-crystalline characteristics of boundary lubrication layers and motor oil rheological characteristics. Proceedings of the 38th International Scientific and Practice Conference, (SPC' 14), "SibAK", Novosibirsk, pp: 46-54.

Slobodyanyuk, D.I., M.A. Kolegayev and I.M. Slobodyanyuk, 2013. Disjoining pressure in thin films of cylinder oil at the iron piston rings of marine diesel engines. Problems Mechan., 2: 43-51.

Shramm, G., 2003. Basics of practical rheology and rheometry. Kolos, Moscow. 